OPEN ACCESS

Edited by:

Yeong Yeh Lee,

University of Science, Malaysia

Reviewed by:

Zheng Feei Ma,

University of Liverpool,

United Kingdom

Askin Erdogan,

Alanya Alaaddin Keykubat University,

Turkey

Mohammad Majharul Haque,

Narayanganj General Hospital,

Bangladesh

*Correspondence:

Toshifumi Ohkusa

ohkusa@juntendo.ac.jp

Specialty section:

This article was submitted to

Gastroenterology,

a section of the journal

Frontiers in Medicine

Received: 29 October 2018

Accepted: 21 January 2019

Published: 12 February 2019

Citation:

Ohkusa T, Koido S, Nishikawa Y and

Sato N (2019) Gut Microbiota and

Chronic Constipation: A Review and

Update. Front. Med. 6:19.

doi: $10.3389 /$ fmed.2019.00019

\section{Gut Microbiota and Chronic Constipation: A Review and Update}

\author{
Toshifumi Ohkusa $^{1,2 *}$, Shigeo Koido ${ }^{2}$, Yuriko Nishikawa ${ }^{1}$ and Nobuhiro Sato ${ }^{1}$ \\ ${ }^{1}$ Department of Microbiota Research, Juntendo University Graduate School of Medicine, Tokyo, Japan, ${ }^{2}$ Department of \\ Gastroenterology and Hepatology, The Jikei University Kashiwa Hospital, Kashiwa, Japan
}

Background: Chronic constipation, including functional constipation and constipation-type irritable bowel syndrome, is a prevalent, multifactorial gastrointestinal disorder, and its etiology and pathophysiology remain poorly understood. Recently studies using $16 \mathrm{~S}$ rRNA-based microbiota profiling have demonstrated dysbiosis of gut microbiota in chronic constipation.

Aims: To provide an overview of recent studies for microbiota in chronic constipation and treatments for chronic constipation using probiotics, prebiotics, synbiotics, antibiotics and fecal microbiota transplantation (FMT).

Methods: PubMed searches were performed up to 1 August 2018 using keywords: "IBS," "IBS-C," "irritable bowel syndrome," "irritable bowel syndrome with constipation," "functional constipation," "chronic constipation" in combination with "gut microbiota," "dysbiosis," "gut microflora" for microbiota in chronic constipation, and in combination with "probiotics," "prebiotics," "synbiotics," "antibiotics," and "fecal microbiota transplantation."

Results: The findings of gut microbiota in functional constipation are inconsistent, and currently no consensus exists. Although no clear consensus exists, compared with healthy subjects, IBS-C patients have a lower level of Actinobacteria, including Bifidobacteria, in their fecal samples and a higher level of Bacteroidetes in their mucosa. In most randomized controlled and parallel-group trials, probiotics, prebiotics, synbiotics, antibiotics, and FMT therapy for chronic constipation were effective with few side effects. However, there are many studies in a small number and the types of probiotics are different, it is difficult to evaluate the effect.

Conclusions: Evidence indicates that dysbiosis of gut microbiota may contribute to functional constipation and constipation-type irritable bowel syndrome. Targeting treatments for the dysbiosis of constipation by probiotics, prebiotics, synbiotics, antibiotics, and FMT may be a new option, especially for refractory constipation to conventional therapies.

Keywords: chronic constipation, functional constipation, irritable bowel syndrome with constipation, gut microbiota, probiotics, synbiotics, antibiotics, FMT 


\section{INTRODUCTION}

Recently, instead of culture methods, molecular approaches based on 16S rDNA gene sequence used to analyze gut microbiota. Advances in the culture independent technologies have shown the enormous diversity, functional capacity, and age-associated dynamics of the human microbiome. A large number of diverse microbial species reside in the distal gastrointestinal tract, and gut microbiota dysbiosis-imbalances in the composition and function of these intestinal microbes-is associated with diseases ranging from localized gastroenterological disorders including constipation to psychoneurotic, respiratory, metabolic, hepatic, and cardiovascular illnesses $(1,2)$.

Functional constipation (FC: Roma classification II-IV) is typically categorized into normal transit constipation (NTC), slow transit constipation (STC), and defecatory or rectal evacuation disorders, based on specific tests such as colonic transition time, manometry evaluation and defecography (Figure 1). The defecatory or rectal evacuation disorders is caused by pelvic floor dyssynergia as well as a reduction in intra-abdominal pressure (act of bearing down), rectal sensory perception, and rectal contraction, suggesting that this type of FC is not related to gut microbiota. In contrast, NTC and STC are associated with gut microbiota. Interestingly, most literature from Western countries reports an association between STC and gut microbiota (3). Chronic constipation that is accompanied by abdominal pain is classified as irritable bowel syndrome with constipation (IBS-C: Roma classification II-IV). Gut microbiota have been shown to play a role in IBS-C.

Until recently, constipation was studied in terms of intestinal function, however many studies have revealed dysbiosis of the gut microbiota in constipated patients compared with healthy controls. In this review, we will summarize the current evidence supporting roles of the gut microbiota in the pathogenesis and treatment of chronic constipation targeting to the dysbiosis of gut microbiota.

\section{GUT MICROBIOTA IN FUNCTIONAL CONSTIPATION}

Reports of dysbiosis in FC (Roma classification II-III criteria) are summarized in Table $\mathbf{1}$ (4-8). All the articles describing gut

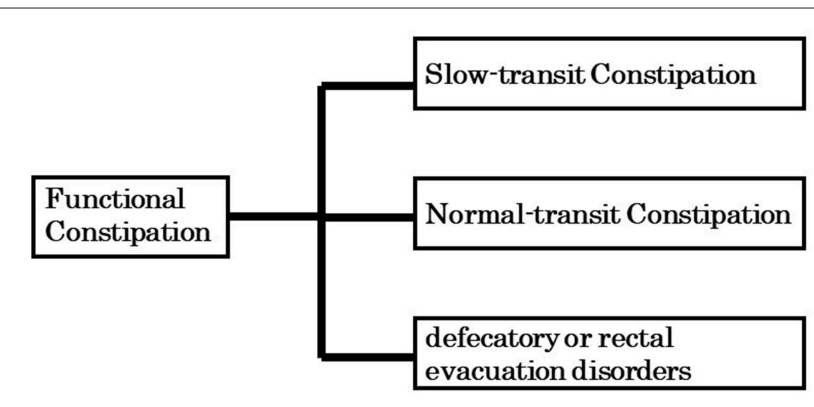

FIGURE 1 | Three broad categories of functional constipation. microbiota of functional constipation and chronic constipation were included (Supplemental Figure 1). Zoppi et al. (4) performed culturing analysis of fecal samples collected from children with FC $(n=28$; mean age $9.5 \mathrm{y})$ and healthy subjects $(n=14$; mean age $7.9 \mathrm{y})$ and demonstrated that the FC patients had a significantly higher level of Clostridium and Bifidobacterium species ( $p<0.001$ and $<0.02$, respectively). They further demonstrated that $C$. sporogenes, $C$. paraputrificum, $C$. fallax, and C. innocuum were dominant among the Clostridium species. Using the same culturing methods, Khalif et al. demonstrated that patients with FC (mean age $42.2 \mathrm{y}$ ) had a reduced level of Bifidobacterium, Lactobacillus, Bacteroides, and Clostridium species and an increased level of Enterobacteriaceae, such as Escherichia coli, as well as Staphylococcus aureus and fungi (5). Zhu et al. (6) used 16S rRNA gene pyrosequencing to demonstrate that patients with FC (mean age $11.8 \mathrm{y}$ ) had a significantly lower level of Bacteroidetes, in particular Prevotella, and an increased level of several species of Firmicutes, including Lactobacillus. The authors further demonstrated that the levels of Lactobacillus and Bifidobacteria species were not reduced. Kim et al. (7) used real-time polymerase chain reaction (qPCR) to demonstrate that patients with FC (mean age $35 \mathrm{y}$ ) had a significantly lower level of Bifidobacterium and Bacteroides (Mann-Whitney $\mathrm{U}$ test; $p=0.030$ and 0.021 , respectively). Whereas, the above studies used fecal samples, more recent studies have examined mucous microbiota by biopsy samples from mucous membranes. Parthasarathy et al. (8) performed $16 \mathrm{~S}$ rRNA metagenomics analysis (V3-V5) and demonstrated that although no difference was present in the amount of bacterial species at the genus level between FC (mean age $48 \mathrm{y}$ ) and healthy control groups, patients with constipation, including those with IBS, had increased levels of Bacteroidetes in their mucosa. However, because the constipation group in this study included 13 FC, 6 IBS-C, and 6 mixed-type IBS patients, the results are not exclusively representative of FC.

These findings are inconsistent, and currently no consensus exists as to which gut microbiota are involved in FC. Because the intestinal flora is changed by age (9). However, some reports are analyzed the intestinal flora of FC in adults and the other reports are analyzed in children. Therefore, it seems to be difficult to explain the association of intestinal flora and FC.

\section{GUT MICROBIOTA IN IRRITABLE BOWEL SYNDROME WITH CONSTIPATION}

Reports of dysbiosis in IBS-C are summarized in Table 2 (1015). In papers studying gut microbiota of IBS, papers reported by data on the constipation type microbiota of IBS included, and papers analyzing microbiota diarrhea type and constipation type together excluded (Supplemental Figure 2).

Using bacterial culture tests, Malinen et al. (10) demonstrated that patients with IBS-C had significantly increased levels of Veillonella species compared with those of healthy controls $(p<0.045)$ as well as higher levels of Lactobacilli compared with those of patients with IBS with diarrhea (IBS-D) $(p<0.019)$. Maukonen et al. (11) analyzed fecal DNA 
TABLE 1 | Dysbiosis in functional constipation.

\begin{tabular}{|c|c|c|c|c|c|}
\hline References & Methods & Materials & Patients & Controls & Outcome \\
\hline Zoppi et al. (4) & Culture & Feces & $\begin{array}{l}\text { FC children }(n=28) \\
\text { (mean age } 9.5 \mathrm{y})\end{array}$ & $\begin{array}{l}\text { HC children }(n=14) \\
\text { (mean age } 7.9 \mathrm{y})\end{array}$ & $\begin{array}{l}\text { FC: Clostridium } \uparrow \\
\text { Bifidobacterium } \uparrow\end{array}$ \\
\hline Khalif et al. (5) & Culture & Feces & $\begin{array}{l}\mathrm{FC}(n=57) \\
(\text { mean age } 42.2 \mathrm{y})\end{array}$ & $\mathrm{HC}(n=25)$ & $\begin{array}{l}\text { FC: Bifidobacterium } \downarrow \\
\text { Lactobacillus } \downarrow \\
\text { Clostridium } \downarrow \\
\text { Bacteroides } \downarrow \\
\text { Enterobacteriaceae (E. coli) } \\
\text { S. aureus } \uparrow \text { Fungi } \uparrow\end{array}$ \\
\hline Zhu et al. (6) & $\begin{array}{l}16 S \text { rRNA } \\
\text { pyrosequencing }\end{array}$ & Feces & $\begin{array}{l}\text { FC children }(n=8) \\
\text { (mean age } 11.8 \mathrm{y})\end{array}$ & $\begin{array}{l}\text { HC children }(n=14) \\
\text { (mean age } 13.2 \mathrm{y})\end{array}$ & $\begin{array}{l}\text { FC: Firmicutes } \uparrow \\
\text { Prevotella } \downarrow\end{array}$ \\
\hline Kim et al. (7) & Quantitative RT-PCR & Feces & $\mathrm{FC}(n=30)($ mean age $35 \mathrm{y})$ & $\begin{array}{l}\mathrm{HC}(n=30) \\
(\text { mean age } 32 \mathrm{y})\end{array}$ & $\begin{array}{l}\text { FC: Bifidobacterium } \downarrow \\
\text { Bacteroides } \downarrow\end{array}$ \\
\hline Parthasarathy et al. (8) & $\begin{array}{l}\text { 16S rRNA Gene } \\
\text { sequencing (V3-V5) }\end{array}$ & $\begin{array}{l}\text { Feces and } \\
\text { Mucosa }\end{array}$ & $\begin{array}{l}\text { FC female }(n=13) \text {, IBS-C } \\
\text { female }(n=6), \\
\text { mixed IBS female }(n=6) \text { (mean } \\
\text { age } 48 \text { y) }\end{array}$ & $\begin{array}{l}\text { HC female }(n=25) \\
\text { (mean age } 39 y)\end{array}$ & FC mucosa: Bacteroidetes $\uparrow$ \\
\hline
\end{tabular}

FC, Functional constipation; HC, Healthy control.

TABLE 2 | Dysbiosis in irritable bowel syndrome with constipation.

\begin{tabular}{|c|c|c|c|c|c|}
\hline References & Methods & Materials & Patients & Controls & Outcome \\
\hline Malinenet al. (10) & Quantitative RT-PCR & Feces & $\begin{array}{l}\text { IBS-C }(n=9) \\
(\text { mean age } 46.5 \mathrm{y})\end{array}$ & $\begin{array}{l}\mathrm{HC}(n=22) \\
(\text { mean age } 45 \mathrm{y})\end{array}$ & IBS-C: Veillonella spp $\uparrow$ \\
\hline Maukonen et al. (11) & $\begin{array}{l}\text { DGGE and Quantitative } \\
\text { RT-PCR }\end{array}$ & Feces & $\begin{array}{l}\text { IBS-C }(n=6) \\
(\text { mean age } 45 \mathrm{y})\end{array}$ & $\begin{array}{l}\mathrm{HC}(n=16) \\
\text { (mean age } 45 \mathrm{y})\end{array}$ & $\begin{array}{l}\text { IBS-C: Clostridium coccoides-E. } \\
\text { rectale group } \downarrow\end{array}$ \\
\hline Rajilić-Stojanović et al. (12) & $\begin{array}{l}\text { Phylogenetic } 16 \mathrm{~S} \text { rRNA } \\
\text { microarray \& } \\
\text { Quantitative RT-PCR }\end{array}$ & Feces & $\begin{array}{l}\text { IBS-C }(n=18) \\
(\text { mean age } 49 y)\end{array}$ & $\begin{array}{l}\mathrm{HC}(n=46) \\
(\text { mean age } 45 \mathrm{y})\end{array}$ & $\begin{array}{l}\text { IBS-C: Firmicutes (Clostridium) } \uparrow \\
\text { Bacteroidetes } \downarrow \\
\text { Actinobacteria } \downarrow\end{array}$ \\
\hline Chassard et al. (13) & Culture & Feces & $\begin{array}{l}\text { IBS-C female }(n=14) \\
\text { (mean age } 48 \mathrm{y})\end{array}$ & $\begin{array}{l}\text { HC female }(n=12) \\
\text { (mean age } 30 \mathrm{y})\end{array}$ & $\begin{array}{l}\text { IBS-C: Enterobacteriaceae } \uparrow \\
\text { Sulfate-reducing bacteria } \uparrow \\
\text { Bifidobacteria } \downarrow \\
\text { Lactobacilli } \downarrow\end{array}$ \\
\hline Durbán et al. (14) & $\begin{array}{l}\text { 16S rRNA gene } \\
\text { sequencing }(\mathrm{V} 1-\mathrm{V} 2)\end{array}$ & Mucosa & $\begin{array}{l}\text { IBS-C }(n=3) \\
\text { (mean age ND) }\end{array}$ & $\begin{array}{l}\mathrm{HC}(n=9) \\
\text { (mean age ND) }\end{array}$ & $\begin{array}{l}\text { IBS-C: Bacteroidetes } \uparrow \\
\text { Enterobacteriaceae } \uparrow\end{array}$ \\
\hline Parkes et al. (15) & $\mathrm{FISH}$ & Mucosa & $\begin{array}{l}\text { IBS-C }(n=20) \\
(\text { mean age } 32.4 \mathrm{y})\end{array}$ & $\begin{array}{l}\mathrm{HC}(n=26) \\
(\text { mean age } 46.1 \mathrm{y})\end{array}$ & $\begin{array}{l}\text { IBS-C: Bacteroidetes } \uparrow \\
\text { Bifidobacteria } \uparrow \\
\text { C. coccoides-Eubacterium rectale } \uparrow\end{array}$ \\
\hline
\end{tabular}

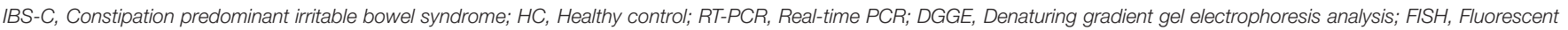
in situ hybridization; ND, No description.

using denaturing gradient gel electrophoresis (DGGE), which revealed that $30 \%$ of all bacterial species in IBS-C patients were Clostridium coccoides and Eubacterium rectale, which was significantly lower than the level in healthy control subjects (43\%; $\mathrm{p}<0.05)$ and IBS-D patients (50\%). Using a phylogenetic $16 S$ rRNA microarray and qPCR, Rajilić-Stojanović et al. (12) demonstrated that patients with IBS-C had a significantly higher level of Firmicutes, including Clostridium species $(p<0.05)$, and a significantly lower level of Actinobacteria and Bacteroidetes $(p<0.01)$ than healthy controls. In a fecal culture experiment, Chassard et al. (13) demonstrated that IBS$C$ patients had significantly higher levels of Enterobacteriaceae $(p=0.0107)$ and sulfate-reducing bacteria $(p=0.0002)$ and significantly lower levels of Bifidobacteria $(p<0.0001)$ and Lactobacillus $(p=0.0007)$.
In studies examining mucosal bacteria, Durbán et al. found an increased level of Bacteroidetes and Enterobacteriaceae in IBS-C patients using 16S rRNA metagenomics analysis (V1-V2) (14). In addition, Parkes et al. demonstrated that IBS-C patients had a higher level of Bacteroidetes, Bifidobacteria, and C. coccoides/E. rectale using fluorescence in situ hybridization (FISH) (15).

Although no clear consensus exists, these studies suggest that compared with healthy subjects, IBS-C patients have a lower level of Actinobacteria, including Bifidobacteria, in their fecal samples and a higher level of Bacteroidetes in their mucosa (Figure 2). The observation that the Bacteroidetes level was high in colonic mucosa is consistent with a previous study by Parthasarathy et al. (8), which examined the mucosal microbiota in FC patients. The intestinal bacteria attached to colonic mucosa may suppress intestinal motility by metabolites produced directly or by them. 


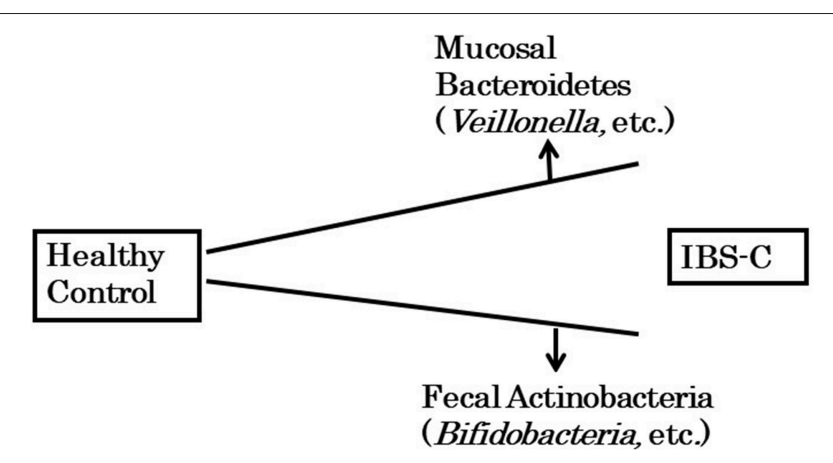

FIGURE 2 | Dysbiosis in IBS-C patient.

\section{TREATMENT OF CHRONIC CONSTIPATION USING PROBIOTICS, PREBIOTICS, AND SYNBIOTICS}

Prebiotics are indigestible carbohydrates, such as oligosaccharide and inulin, that increase the amount of probiotics, such as Bifidobacteria and Lactobacillus, that are commonly present in humans. The algorithm the studies included in the review is shown in Supplemental Figure 3. Table 3 summarizes RCTs that have investigated the effects of these prebiotics, probiotics and synbiotics (16-37).

Bouhnik et al. (16) administered lactulose ( $\beta$-Dgalactopyranosyl-( $1 \rightarrow 4)$-D-fructose), an indigestible carbohydrate, and demonstrated that it was as effective as polyethylene glycol (a laxative) in relieving constipation. They further examined fecal samples of these patients and demonstrated a significant increase in the level of Bifidobacteria in the lactulose group $(p=0.04)$, whereas in the polyethylene glycol group showed no increase in Bifidobacteria, and the total amount of bacteria was decreased. In a study by Linetzky Waitzberg el al. (17), inulin was shown to have the equivalent effect of a placebo (maltodextrin) on constipation. They further demonstrated that patients who received inulin but not maltodextrin exhibited a decrease in Clostridium species in their fecal samples. However, because maltodextrin contains indigestible components, it may not have been an appropriate placebo.

Lactobacillus and Bifidobacteria are commonly used as probiotics in adults (18-26) and in children (27-31). Koebnick et al. (18) performed the first RCT in 2003, in which the $L$. casei Shirota strain (LcS) was administered to 35 patients with chronic constipation. Compared to placebo $(n=35)$, patients who received LcS had a significantly improved defecation frequency and stool consistency 2 weeks after administration $(p<0.0001)$. At the 5 -week post-administration endpoint, the $\mathrm{LcS}$ group demonstrated significant improvement compared to the placebo control, with 89 and 56\% improvement, respectively $(p=0.003)$. As seen in Table 3, all studies in adults indicated the effectiveness of probiotics for treating constipation. Ishizuka et al. performed a crossover study by administering either $10^{10}$ $\mathrm{cfu} / 100 \mathrm{~mL}$ of $B$. lactis GCL2505 or a milk product without bacteria as a placebo in 17 patients with constipation. Two weeks after administration, patients who received $B$. lactis had a significant increase in defecation frequency and the amount of stool (19). Because the patients had a higher quantity of B. lactis in their feces, the authors concluded that bacterial growth may have contributed to the improvement in constipation symptoms. Recently, Yoon et al. conducted RCT by administering $3.0 \times$ $108 \mathrm{CFU} / \mathrm{g}$ of Streptococcus thermophilus MG510 and $1.0 \times$ $108 \mathrm{CFU} / \mathrm{g}$ of Lactobacillus plantarum LRCC5193 with 171 cases in many cases (26). They concluded that the probiotics significantly ameliorated stool consistency in patients with chronic constipation. In addition, the beneficial effect of $L$. plantarum on stool consistency remained after the probiotic supplementation was discontinued. In children, constipation is a clinically significant problem, and many RCTs by administration of probiotics are done. Bu et al. evaluate the efficacy of probiotics (Lactobacillus casei rhamnosus, Lcr35) for treating children with chronic constipation and to compare its effect with magnesium oxide (MgO) and placebo (27). They reported that Lcr35 was effective in treating children with chronic constipation. There is no statistically significant difference in efficacy between $\mathrm{MgO}$ and Lcr35, but less abdominal pain occurred when using Lcr35. However, recent RCT studies by Tabbers et al. (30) and Wojtyniak et al. (31) reported no significant effect of Bifidobacterium lactis and Lcr35 for functional constipation when compared with placebo.

Bazzocchi et al. (36) described a synbiotic treatment regimen, in which plantain fiber was used as a prebiotic in addition to a probiotic cocktail containing five species of live Lactobacillus and Bifidobacteria. They administered either the synbiotic $(n=17)$ or maltodextrin (placebo) $(n=12)$ for 8 weeks and demonstrated that patients receiving the synbiotic had a significant improvement in defecation frequency and stool consistency $(p=0.001)$. In addition, the colonic transition time was significantly reduced in the synbiotic group ( $p=0.022$ ), and the five species of Lactobacillus that were administered, including $L$. planetarium, L. acidophilus, and L. rhamnosus, were found in the fecal samples of half of the patients in the synbiotic group. Khodadad et al. (33) and Sadeghzadeh et al. (35) done RCT of constipation treatment of the same multiple kinds of probiotics administration (Lactobacillus casei, Lactobacillus rhamnosus, Streptococcus thermophiles, Bifidobacterium breve, Lactobacillus acidophilus, Bifidobacterium infantis, and Lactobacillus bulgaricus). The studies showed that synbiotics have positive effects on symptoms of childhood constipation without any side effects. However, Branaskiewicz et al. (32) and Lim et al. (37) reported that synbiotics were not an effective in treating constipation. They suggested that the result was due to the high placebo effect which synbiotics failed to demonstrate benefit over the controls.

Few side effects such as abdominal pain, abdominal distention, vomiting $(16,30,32)$ were reported in the studies described above, indicating that administration of these agents is safe. Therefore, probiotics, prebiotics, and synbiotics may be effective treatment options for constipation. Because there are many studies in a small number and the types of probiotics are different, 
TABLE 3 | Randomized controlled and parallel-group trials of prebiotics, probiotics and synbiotics for chronic constipation.

\begin{tabular}{|c|c|c|c|c|c|}
\hline References & Interventions (n) & Controls (n) & Prebiotics or Probiotics & $\begin{array}{l}\text { Control } \\
\text { materials }\end{array}$ & Outcome \\
\hline \multicolumn{6}{|l|}{ PREBIOTICS } \\
\hline Linetzky Waitzberg et al. (17) & $\begin{array}{l}28 \text { female } \\
\text { (mean age } 36.1 \mathrm{y})\end{array}$ & $\begin{array}{l}32 \text { female } \\
\text { (mean age } 40.2 \mathrm{y})\end{array}$ & Inulin & Maltodextrin & No significant differences \\
\hline Yang et al. (19) & $\begin{array}{l}63 \text { female } \\
\text { (mean age } 46.4 \text { y) }\end{array}$ & $\begin{array}{l}63 \text { female } \\
\text { (mean age } 46.4 \mathrm{y})\end{array}$ & B. lactis & $\begin{array}{l}\text { Acidified milk } \\
\text { without probiotics }\end{array}$ & $\begin{array}{l}\text { Defecation frequency } \uparrow \\
(p<0.01) \\
\text { Stool consistency } \downarrow \\
(p<0.01) \\
\text { Defecation condition } \downarrow \\
(p<0.01)\end{array}$ \\
\hline Waller et al. (20) & $\begin{array}{l}\text { High dose } 33 \\
\text { (mean age } 43 \text { y) Low } \\
\text { dose } 33 \\
\text { (mean age } 44 \text { y) }\end{array}$ & $\begin{array}{l}34 \\
\text { (mean age } 45 y)\end{array}$ & B. lactis & $\begin{array}{l}\text { Capsules with rice } \\
\text { Maltodextrin }\end{array}$ & $\begin{array}{l}\text { Abd pain } \downarrow(p<0.001) \\
\text { Constipation } \downarrow(p<0.001) \\
\text { Irregular bowel movement } \downarrow \\
(P<0.01) \\
\text { Flatulence } \downarrow \\
(p<0.05)\end{array}$ \\
\hline Ishizuka et al. (21) & $\begin{array}{l}17 \text { female } \\
\text { (cross over) } \\
\text { (age range 20-23 y) }\end{array}$ & $\begin{array}{l}17 \text { female } \\
\text { (age range 20-23 y) }\end{array}$ & B. lactis & Milk-like drink & $\begin{array}{l}\text { Defecation frequency } \uparrow \\
(p<0.05)\end{array}$ \\
\hline Riezzo et al. (22) & $\begin{array}{l}20 \text { (cross over) } \\
\text { (mean age } 38.8 \text { y) }\end{array}$ & $\begin{array}{l}20 \\
(\text { mean age } 38.8 y)\end{array}$ & L. paracasei & $\begin{array}{l}\text { Artichokes without } \\
\text { probiotics }\end{array}$ & $\begin{array}{l}\text { Satisfactory relief of symptom } \\
(p=0.0014) \\
\text { Stool consistency } \downarrow(p=0.009)\end{array}$ \\
\hline Yoon et al. (26) & $\begin{array}{l}\text { IBS-C \& FC, } 88 \\
\text { (mean age } 38.3 \text { y) }\end{array}$ & $\begin{array}{l}83 \\
\text { (mean age } 39.4 \mathrm{y})\end{array}$ & $\begin{array}{l}\text { S. thermophilus, } \\
\text { L. plantarum }\end{array}$ & Chocolate & $\begin{array}{l}\text { Stool consistency } \downarrow \\
(p=0.002) \\
\text { QOL score } \uparrow \\
(p=0.044)\end{array}$ \\
\hline \multicolumn{6}{|l|}{ PROBIOTICS IN CHILDREN } \\
\hline Bu et al. (27) & $\begin{array}{l}\text { Children A: } 18 \\
\text { (mean age } 32.4 \mathrm{mo} \text { ) } \\
\text { Children B: } 18 \\
\text { (mean age } 36.7 \mathrm{mo} \text { ) }\end{array}$ & $\begin{array}{l}\text { Children C: } 9 \\
\text { (mean age } 35 \text { mo) }\end{array}$ & $\begin{array}{l}\text { Children A: MgO Children } \\
\text { B: L. casei rhamnosus }\end{array}$ & Children C: starch & $\begin{array}{l}\text { Defecation frequency } \uparrow \\
(p=0.03) \\
\text { Hard stool } \downarrow(p=0.01) \\
\text { Abd pain } \downarrow(p=0.03)\end{array}$ \\
\hline Coccorullo et al. (28) & $\begin{array}{l}\text { Infants } 22 \\
\text { (mean age } 8.2 \text { mo) }\end{array}$ & $\begin{array}{l}\text { Infants } 22 \\
\text { (mean age } 8.8 \text { mo) }\end{array}$ & L. reuteri & Identical placebo & $\begin{array}{l}\text { Bowel movements } \uparrow \\
(p=0.008 \sim 0.042)\end{array}$ \\
\hline Guerra et al. (29) & $\begin{array}{l}\text { Children } 30 \\
\text { (cross over) } \\
\text { (age 5 15 y) }\end{array}$ & $\begin{array}{l}\text { Children } 29 \\
\text { (cross over) } \\
\text { (age 5 15 y) }\end{array}$ & $\begin{array}{l}\text { B. longum }+ \\
\text { S. thermophilus }\end{array}$ & $\begin{array}{l}\text { L. delbrueckii } \\
\text { subsp. bulgaricus } \\
+ \text { S. thermophilus }\end{array}$ & $\begin{array}{l}\text { Defecation frequency } \uparrow \\
(p=0.012) \\
\text { Defecation pain } \downarrow \\
(p=0.046) \\
\text { Abd pain } \downarrow(p=0.015)\end{array}$ \\
\hline
\end{tabular}


TABLE 3 | Continued

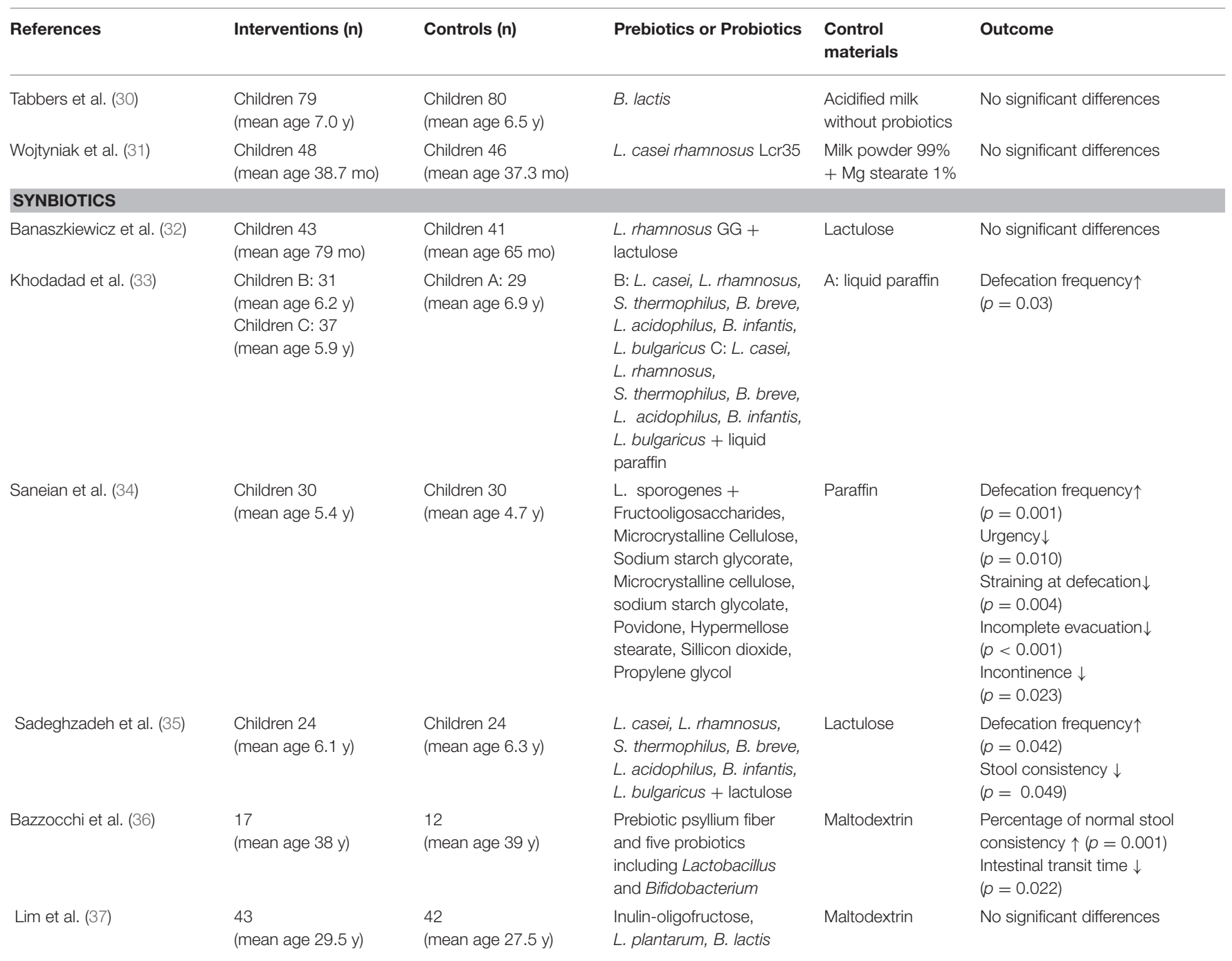

it is difficult to evaluate the effect. Therefore, it will be necessary to conduct a number of studies on specific probiotics.

\section{TREATMENT OF CHRONIC CONSTIPATION USING ANTIMICROBIAL AGENTS}

Previous studies have proposed a link between constipation and methanogenic bacteria via the hypothesis that methanogenic gut microbiota lead to the development of constipation by reducing bowel movement (38). Studies have shown that patients with chronic constipation have more methanogenic bacteria than healthy subjects $(39,40)$.

In a study by Low et al. (41), IBS-C patients with $>3 \mathrm{ppm}$ methane production were treated with rifaximin and neomycin for 10 days, and the changes in symptoms and breath testing outcomes were examined using lactulose breath testing. Patients received neomycin and rifaximin $(n=27)$, neomycin alone $(n=8)$, or rifaximin alone $(n=39)$. Symptoms improved in 85 , 63 , and $56 \%$ of patients, respectively, demonstrating a significant improvement in the neomycin + rifaximin group compared with the rifaximin alone group $(p=0.01)$. Furthermore, patients who received neomycin + rifaximin had a significantly reduced level of methanogenic bacteria. Eighty-seven percent of patients had a methane production level of $<3 \mathrm{ppm}$, as measured by breath testing, compared to $33 \%$ in the neomycin group $(p=0.001)$ and $28 \%$ in the rifaximin group $(p=0.001)$. Therefore, the authors concluded that the combination of rifaximin and neomycin was effective in the treatment of IBS-C associated with methane production (37). This study presented interesting findings that support the association between constipation and methanogenic bacteria.

\section{TREATMENT OF CHRONIC CONSTIPATION BY FECAL MICROBIOTA TRANSPLANTATION}

The algorithm the studies included in the review is shown in Supplemental Figure 4. Table 4 summarizes studies (42-47) on 
TABLE 4 | Fecal microbiota transplantation (FMT) for chronic constipation.

\begin{tabular}{|c|c|c|c|c|c|}
\hline References & Study & Interventions (n) & Controls (n) & Follow-up Period & Outcome \\
\hline Borody et al. (42) & Case series & 4 & - & 28 months & Defecation frequency $\uparrow$ \\
\hline Andrews et al. (43) & Case report & 1 & - & 18 months & $\begin{array}{l}\text { Defecation frequency } \uparrow \\
\text { Melanosis coli disappeared }\end{array}$ \\
\hline Ge et al. (44) & Case series & 6 & - & 12 weeks & $\begin{array}{l}\text { Defecation frequency } \uparrow(P<0.05) \\
\text { Stool consistency } \downarrow(P<0.05) \\
\text { Colonic transit time } \downarrow(P<0.05)\end{array}$ \\
\hline Tian et al. (45) & $\mathrm{RCT}$ & 30 & 30 & 12 weeks & $\begin{array}{l}\text { Defecation frequency } \uparrow(p=0.001) \\
\text { Stool consistency } \downarrow(P<0.00001) \\
\text { Colonic transit time } \downarrow(P<0.00001) \\
\text { Clinical cure rate } \uparrow(p=0.04) \\
\text { Clinical improvement rate } \uparrow(p=0.009)\end{array}$ \\
\hline Ding et al. (46) & Case series & 52 & - & 24 weeks & $\begin{array}{l}\text { Defecation frequency } \uparrow(P<0.01) \\
\text { Stool consistency } \downarrow(P<0.01) \\
\text { Incompleteness of evacuation } \downarrow(P<0.01) \\
\text { Colonic transit time } \downarrow(P<0.01)\end{array}$ \\
\hline Zhang et al. (47) & Case series & 29 & - & 1 year & $\begin{array}{l}\text { Complete spontaneous bowel movement, stool } \\
\text { consistency, the Wexner constipation scale and } \\
\text { constipation symptoms improved }\end{array}$ \\
\hline
\end{tabular}

RCT, Randomized controlled trials.

the treatment of refractory constipation by fecal microbiota transplantation (FMT). Borody et al. (42) performed FMT on 4 patients with chronic constipation and demonstrated immediate improvements in symptoms, such as abdominal pain, early satiety, and nausea, as well as a significant improvement in defecation frequency to once or twice daily. Furthermore, in a case report of a patient with refractory constipation, the authors demonstrated that FMT effectively induced defecation 2-3 days after the transplant, with a defecation frequency of once or twice daily (43). Ge et al. (44) performed FMT on 6 patients with STC and demonstrated a significant increase in defecation frequency, from $1.6 \pm 0.2$ times a week at pretreatment to $5.0 \pm 0.4$ times a week at 12 weeks posttreatment $(p<0.001)$, as well as in stool consistency from $2.0 \pm 0.3$ at pretreatment to $3.3 \pm 0.2$ at 12 weeks posttreatment $(p=0.0025)$. They also performed 16S rRNA metagenomics analysis on fecal microbiota prior to FMT and demonstrated that patients with constipation had an increased quantity and diversity of bacteria compared to healthy subjects. However, they did not perform this analysis following FMT to detect changes that may have occurred in the fecal microbiota. Tian et al. (45) performed an RCT in which 60 patients with STC were divided into either the FMT or control group and received a conventional laxative. The comparison of the FMT $(n=25)$ and control $(n=24)$ patients who completed the study demonstrated that those who underwent FMT had significantly improved symptoms, including defecation frequency and fecal properties. Therefore, they concluded that FMT for constipation was effective, although the sample size was small. However, it is unlikely that FMT will be considered as a first choice given the challenges in identifying donors as well as the cost and complexity of the procedure. FMT should be selectively performed in patients who are refractory to conventional therapeutic strategies.

\section{CONCLUSIONS AND FUTURE PERSPECTIVES}

Constipation is a syndrome indicating various and complex combinations of disorders. Given its complexity, clinical trials, such as those performed for single diseases, may not be possible. Most studies use the Rome criteria to diagnose constipation and perform functional tests to selectively target patients with STC for trials. Results from clinical studies on probiotics and FMT suggest that constipation is caused by dysbiosis of the microbiota. Thus, future studies should be performed by first categorizing constipation to identify the target population. In addition, studies on gut microbiota may identify bacterial species that promote the development of constipation. Ultimately, the identification of causative bacteria of constipation may lead to the development of probiotic, prebiotic, and synbiotic treatments that can cure constipation in the future.

\section{AUTHOR CONTRIBUTIONS}

TO, SK, and NS wrote and edited the manuscript. TO created the figure and critically revised the manuscript. YN gathered the documents and created tables. All authors read and approved the final manuscript for publication.

\section{FUNDING}

The Department of Microbiota Research is supported by Morinaga Milk Industry Co., Ltd. as a donation course.

\section{SUPPLEMENTARY MATERIAL}

The Supplementary Material for this article can be found online at: https://www.frontiersin.org/articles/10.3389/fmed. 2019.00019/full\#supplementary-material 


\section{REFERENCES}

1. Lynch SV, Pedersen O. The human intestinal microbiome in health and disease. N Engl J Med. (2016) 375:2369-79. doi: 10.1056/NEJMra1600266

2. Yusof N, Hamid N, Ma ZF, Lawenko RM, Wan Mohammad WMZ, Collins DA, et al. Exposure to environmental microbiota explains persistent abdominal pain and irritable bowel syndrome after a major flood. Gut Pathog. (2017) 9:75. doi: 10.1186/s13099-017-0224-7

3. Simrén M, Barbara G, Flint HJ, Spiegel BM, Spiller RC, Vanner S, et al. Intestinal microbiota in functional bowel disorders: a Rome foundation report. Gut (2013) 62:159-76. doi: 10.1136/gutjnl-2012-302167

4. Zoppi G, Cinquetti M, Luciano A, Benini A, Muner A, Bertazzoni Minelli E. The intestinal ecosystem in chronic functional constipation. Acta Paediatr. (1998) 87:836-41. doi: 10.1111/j.1651-2227.1998.tb01547.x

5. Khalif IL, Quigley EM, Konovitch EA, Maximova ID. Alterations in the colonic flora and intestinal permeability and evidence of immune activation in chronic constipation. Dig Liver Dis. (2005) 37:838-49. doi: 10.1016/j.dld.2005.06.008

6. Zhu L, Liu W, Alkhouri R, Baker RD, Bard JE, Quigley EM, et al. Structural changes in the gut microbiome of constipated patients. Physiol Genomics (2014) 46:679-86. doi: 10.1152/physiolgenomics.00082.2014

7. Kim SE, Choi SC, Park KS, Park MI, Shin JE, Lee TH, et al. Change of fecal flora and effectiveness of the short-term VSL\#3 Probiotic treatment in patients with functional constipation. J Neurogastroenterol Motil. (2015) 21:111-20. doi: 10.5056/jnm14048

8. Parthasarathy G, Chen J, Chen X, Chia N, O'Connor HM, Wolf PG, et al. Relationship between microbiota of the Colonic Mucosa vs feces and symptoms, colonic transit, and methane production in female patients with chronic constipation. Gastroenterology (2016) 150:367-79. doi: 10.1053/j.gastro.2015.10.005

9. Yatsunenko T, Rey FE, Manary MJ, Trehan I, Dominguez-Bello MG, Contreras $\mathrm{M}$, et al. Human gut microbiome viewed across age and geography. Nature (2012) 486:222-7. doi: 10.1038/nature11053

10. Malinen E, Rinttilä T, Kajander K, Mättö J, Kassinen A, Krogius L, et al. Analysis of the fecal microbiota of irritable bowel syndrome patients and healthy controls with real-time PCR. Am J Gastroenterol. (2005) 100:373-82. doi: 10.1111/j.1572-0241.2005.40312.x

11. Maukonen J, Satokari R, Mättö J, Söderlund H, Mattila-Sandholm T, Saarela M. Prevalence and temporal stability of selected clostridial groups in irritable bowel syndrome in relation to predominant faecal bacteria. J Med Microbiol. (2006) 55:625-33. doi: 10.1099/jmm.0.46134-0

12. Rajilić-Stojanović M, Biagi E, Heilig HG, Kajander K, Kekkonen RA, Tims $\mathrm{S}$, et al. Global and deep molecular analysis of microbiota signatures in fecal samples from patients with irritable bowel syndrome. Gastroenterology (2011) 141:1792-801. doi: 10.1053/j.gastro.2011.07.043

13. Chassard C, Dapoigny M, Scott KP, Crouzet L, Del'homme C, Marquet P, et al. Functional dysbiosis within the gut microbiota of patients with constipatedirritable bowel syndrome. Aliment Pharmacol Ther. (2012) 35:828-38. doi: 10.1111/j.1365-2036.2012.05007.x

14. Durbán A, Abellán JJ, Jiménez-Hernández N, Salgado P, Ponce M, Ponce J, et al. Structural alterations of faecal and mucosa-associated bacterial communities in irritable bowel syndrome. Environ Microbiol Rep. (2012) 4:242-7. doi: 10.1111/j.1758-2229.2012.00327.x

15. Parkes GC, Rayment NB, Hudspith BN, Petrovska L, Lomer MC, Brostoff J, et al. Distinct microbial populations exist in the mucosa-associated microbiota of sub-groups of irritable bowel syndrome. Neurogastroenterol Motil. (2012) 24:31-9. doi: 10.1111/j.1365-2982.2011.01803.x

16. Bouhnik Y, Neut C, Raskine L, Michel C, Riottot M, Andrieux C, et al. Prospective, randomized, parallel-group trial to evaluate the effects of lactulose and polyethylene glycol-4000 on colonic flora in chronic idiopathic constipation. Aliment Pharmacol Ther. (2004) 19:889-99. doi: 10.1111/j.1365-2036.2004.01918.x

17. Linetzky Waitzberg D, Alves Pereira CC, Logullo L, Manzoni Jacintho T, Almeida D, Teixeira da Silva ML, et al. Microbiota benefits after inulin and partially hydrolized guar gum supplementation: a randomized clinical trial in constipated women. Nutr Hosp. (2012) 27:123-9. doi: 10.1590/S0212-16112012000100014
18. Koebnick C, Wagner I, Leitzmann P, Stern U, Zunft HJ. Probiotic beverage containing Lactobacillus casei Shirota improves gastrointestinal symptoms in patients with chronic constipation. Can J Gastroenterol. (2003) 17:655-9. doi: 10.1155/2003/654907

19. Yang YX, He M, Hu G, Wei J, Pages P, Yang XH, et al. Effect of a fermented milk containing Bifidobacterium lactis DN-173010 on Chinese constipated women. World J Gastroenterol. (2008) 14:6237-43. doi: 10.3748/wjg.14.6237

20. Waller PA, Gopal PK, Leyer GJ, Ouwehand AC, Reifer C, Stewart ME, et al. Dose-response effect of Bifidobacterium lactis HN019 on whole gut transit time and functional gastrointestinal symptoms in adults. Scand J Gastroenterol. (2011) 46:1057-64. doi: 10.3109/00365521.2011.584895

21. Ishizuka A, Tomizuka K, Aoki R, Nishijima T, Saito Y, Inoue R, et al. Effects of administration of Bifidobacterium animalis subsp. lactis GCL2505 on defecation frequency and bifidobacterial microbiota composition in humans. J Biosci Bioeng. (2012) 113:587-91. doi: 10.1016/j.jbiosc.2011.12.016

22. Riezzo G, Orlando A, D'Attoma B, Guerra V, Valerio F, Lavermicocca P, et al. Randomised clinical trial: efficacy of Lactobacillus paracasei-enriched artichokes in the treatment of patients with functional constipation-a doubleblind, controlled, crossover study. Aliment Pharmacol Ther. (2012) 35:441-50. doi: 10.1111/j.1365-2036.2011.04970.x

23. Favretto DC, Pontin B, Moreira TR. Effect of the consumption of a cheese enriched with probiotic organisms (Bifidobacterium lactis bi-07) in improving symptoms of constipation. Arq Gastroenterol. (2013) 50:196-201. doi: 10.1590/S0004-28032013000200035

24. Mazlyn MM, Nagarajah LH, Fatimah A, Norimah AK, Goh KL. Effects of a probiotic fermented milk on functional constipation: a randomized, doubleblind, placebo-controlled study. J Gastroenterol Hepatol. (2013) 28:1141-7. doi: 10.1111/jgh.12168

25. Mezzasalma V, Manfrini E, Ferri E, Sandionigi A, La Ferla B, Schiano I, et al. A randomized, double-blind, placebo-controlled trial: the efficacy of multispecies probiotic supplementation in alleviating symptoms of irritable bowel syndrome associated with constipation. Biomed Res Int. (2016) 2016:4740907. doi: 10.1155/2016/4740907

26. Yoon JY, Cha JM, Oh JK, Tan PL, Kim SH, Kwak MS, et al. Probiotics ameliorate stool consistency in patients with chronic constipation: a randomized, double-blind, placebo-controlled study. Dig Dis Sci. (2018) 63:2754-64. doi: 10.1007/s10620-018-5139-8

27. Bu LN, Chang $\mathrm{MH}, \mathrm{Ni} \mathrm{YH}$, Chen HL, Cheng CC. Lactobacillus casei rhamnosus Lcr35 in children with chronic constipation. Pediatr Int. (2007) 49:485-90. doi: 10.1111/j.1442-200X.2007.02397.x

28. Coccorullo P, Strisciuglio C, Martinelli M, Miele E, Greco L, Staiano A. Lactobacillus reuteri (DSM 17938) in infants with functional chronic constipation: a double-blind, randomized, placebo-controlled study. J Pediatr. (2010) 157:598-602. doi: 10.1016/j.jpeds.2010.04.066

29. Guerra PV, Lima LN, Souza TC, Mazochi V, Penna FJ, Silva AM, et al. Pediatric functional constipation treatment with Bifidobacterium-containing yogurt: a crossover, double-blind, controlled trial. World J Gastroenterol. (2011) 17:3916-21. doi: 10.3748/wjg.v17.i34.3916

30. Tabbers MM, Chmielewska A, Roseboom MG, Crastes N, Perrin C, Reitsma JB, et al. Fermented milk containing Bifidobacterium lactis DN-173 010 in childhood constipation: a randomized, double-blind, controlled trial. Pediatrics (2011) 127:e1392-9. doi: 10.1542/peds.2010-2590

31. Wojtyniak K, Horvath A, Dziechciarz P, Szajewska H. Lactobacillus casei rhamnosus Lcr35 in the management of functional constipation in children: a randomized trial. J Pediatr. (2017) 184:101-5. doi: 10.1016/j.jpeds.2017.01.068

32. Banaszkiewicz A, Szajewska H. Ineffectiveness of Lactobacillus GG as an adjunct to lactulose for the treatment of constipation in children: a doubleblind, placebo-controlled randomized trial. J Pediatr. (2005) 146:364-9. doi: $10.1016 /$ j.jpeds.2004.10.022

33. Khodadad A, Sabbaghian M. Role of synbiotics in the treatment of childhood constipation: a double-blind randomized placebo controlled trial. Iran J Pediatr. (2010) 20:387-92.

34. Saneian H, Tavakkol K, Adhamian P, Gholamrezaei A. Comparison of Lactobacillus sporogenes plus mineral oil and mineral oil alone in the treatment of childhood functional constipation. J Res Med Sci. (2013) 18:85-8.

35. Sadeghzadeh M, Rabieefar A, Khoshnevisasl P, Mousavinasab N, Eftekhari K. The effect of probiotics on childhood constipation: a randomized 
controlled double-blind clinical trial. Int J Pediatr. (2014) 2014:937212. doi: 10.1155/2014/937212

36. Bazzocchi G, Giovannini T, Giussani C, Brigidi P, Turroni S. Effect of a new synbiotic supplement on symptoms, stool consistency, intestinal transit time and gut microbiota in patients with severe functional constipation: a pilot randomized double-blind, controlled trial. Tech Coloproctol. (2014) 18:945-53. doi: 10.1007/s10151-014-1201-5

37. Lim YJ, Jamaluddin R, Hazizi AS, Chieng JY. Effects of synbiotics among constipated adults in serdang, selangor, malaysia-a randomised, double-blind, placebo-controlled trial. Nutrients (2018) 10:824. doi: 10.3390/nu10070824

38. Sahakian AB, Jee SR, Pimentel M. Methane and the gastrointestinal tract. Dig Dis Sci. (2010) 55:2135-43. doi: 10.1007/s10620-009-1012-0

39. Lee KM, Paik CN, Chung WC, Yang JM, Choi MG. Breath methane positivity is more common and higher in patients with objectively proven delayed transit constipation. Eur J Gastroenterol Hepatol. (2013) 25:726-32. doi: 10.1097/MEG.0b013e32835eb916

40. Attaluri A, Jackson M, Valestin J, Rao SS. Methanogenic flora is associated with altered colonic transit but not stool characteristics in constipation without IBS. Am J Gastroenterol. (2010) 105:1407-11. doi: 10.1038/ajg.2009.655

41. Low K, Hwang L, Hua J, Zhu A, Morales W, Pimentel M. A combination of rifaximin and neomycin is most effective in treating irritable bowel syndrome patients with methane on lactulose breath test. J Clin Gastroenterol. (2010) 44:547-50. doi: 10.1097/MCG.0b013e3181c64c90

42. Borody TJ, George L, Andrews P, Brandl S, Noonan S, Cole P, et al. Bowel-flora alteration: a potential cure for inflammatory bowel disease and irritable bowel syndrome? Med J Aust. (1989) 150:604.

43. Andrews PJ, Barnes P, Borody TJ Chronic constipation reversed by restoration of bowel flora. A case and a hypothesis. Eur J Gastroenterol Hepatol. (1992) 4:245-7.
44. Ge X, Zhao W, Ding C, Tian H, Xu L, Wang H, et al. Potential role of fecal microbiota from patients with slow transit constipation in the regulation of gastrointestinal motility. Sci Rep. (2017) 7:441. doi: 10.1038/s41598-017-00612-y

45. Tian H, Ge X, Nie Y, Yang L, Ding C, McFarland LV, et al. Fecal microbiota transplantation in patients with slow-transit constipation: a randomized, clinical trial. PLoS ONE (2017) 12:e0171308. doi: 10.1371/journal.pone. 0171308

46. Ding C, Fan W, Gu L, Tian H, Ge X, Gong J, et al. Outcomes and prognostic factors of fecal microbiota transplantation in patients with slow transit constipation: results from a prospective study with longterm follow-up. Gastroenterol Rep. (2018) 6:101-7. doi: 10.1093/gastro/ gox036

47. Zhang X, Tian H, Gu L, Nie Y, Ding C, Ge X, et al. Long-term follow-up of the effects of fecal microbiota transplantation in combination with soluble dietary fiber as a therapeutic regimen in slow transit constipation. Sci China Life Sci. (2018) 61:779-86. doi: 10.1007/s11427-017-9229-1

Conflict of Interest Statement: The authors declare that the research was conducted in the absence of any commercial or financial relationships that could be construed as a potential conflict of interest.

Copyright $\odot 2019$ Ohkusa, Koido, Nishikawa and Sato. This is an open-access article distributed under the terms of the Creative Commons Attribution License (CC BY). The use, distribution or reproduction in other forums is permitted, provided the original author(s) and the copyright owner(s) are credited and that the original publication in this journal is cited, in accordance with accepted academic practice. No use, distribution or reproduction is permitted which does not comply with these terms. 